\title{
The Effect of Transition Metal on the Optical Properties and Photoactivity of Nano-particulate Titanium Dioxide
}

\author{
Liwei Wang ${ }^{1} \&$ Terry Egerton ${ }^{2}$ \\ ${ }^{1}$ Department of Chemistry and Chemical Engineering, Minjiang University, Fuzhou, China \\ ${ }^{2}$ School of Chemical Engineering and Advanced Materials, Newcastle University, Newcastle, UK \\ Correspondence: Liwei Wang, Department of Chemistry and Chemical Engineering, Minjiang University, \\ Fuzhou 350108, China. E-mail: liweiwangy@hotmail.com
}

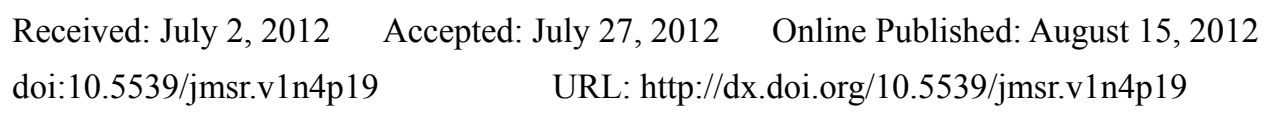

\begin{abstract}
Transition metal (vanadium, chromium, iron) doped $\mathrm{TiO}_{2}$ was synthesised by co-precipitation or by surface-deposition. The specimens were characterised by XRD and reflectance spectroscopy. In terms of the structure, the surface doped samples are same as those made by co-precipitation nor did the presence of metal ions change the structure. The presence of transition metal induced a shift of light absorption of the doped $\mathrm{TiO}_{2}$ to visible wavelengths. The introduction of transition metal ions into $\mathrm{TiO}_{2}$ significantly affected the photoactivity, which was determined by the oxidation of IPA and photogreying. As a general trend, an optimum dopant appeared which gave the maximum photoactivity. It was found that the photoactivity of co-precipitated samples was lower than that of surface-doped. The photoactivity of doped $\mathrm{TiO}_{2}$ is a function of many parameters, such as the dopant content, energy level of dopant, the $d$ electronic configuration of dopant ions and the distribution of dopant. These factors influence IPA photo-oxidation and photogreying to different extents.
\end{abstract}

Keywords: titanium dioxide, doping, photoactivity, transition metal

\section{Introduction}

Doping with transition ions may affect photocatalysis by $\mathrm{TiO}_{2}$ in a number of ways. Doping extends the absorption to longer wavelengths beyond the normal absorption edge of anatase (385 $\mathrm{nm})$ and rutile (405 $\mathrm{nm})$ and therefore can lead to more effective harvesting of the photons of solar radiation (Nunes, 2008; Karvinen, 2003; Karvinen \& Lamminmaki, 2003; Wilke, 1999; Khan, 2008). Transition ion dopants may also act as centres at which excited electrons may recombine with holes that could otherwise initiate formation of catalytically active hydroxyl radicals at the $\mathrm{TiO}_{2}$ surface (Choi, 1994; Ikeda, 2001; Paola, 2004; Zhang, 1998). In this way the photocatalytic activity of the $\mathrm{TiO}_{2}$ is reduced. However, if the transition metal ions, e.g. Fe(III), effectively capture only excited electrons, electron-hole recombination may be reduced and therefore photocatalysis will be promoted (Wang, 2003). Crystal defects and surface modifications, may also alter the photoactivity of $\mathrm{TiO}_{2}$ (Karvinen \& Lamminmaki, 2003). The balance of these effects will depend on the details of the UV excitation, the form of the $\mathrm{TiO}_{2}-$ e.g. whether it is anatase or rutile, the method of synthesis and on the crystal size and the photocatalytic activity cannot therefore be routinely predicted (Chen, 2008; Yang, 2008). This paper is concerned with the effect of iron, vanadium and chromium on the photoactivity of nanoparticulate rutile.

The reported effects of iron doping on photocatalytic oxidation are variable. Co-precipitated and impregnated macroporous iron-doped anatase has shown high efficiency for photoreduction of dinitrogen to ammonia (Soria, 1991). However Navio concluded that the photoactivity of Fe-doped $\mathrm{TiO}_{2}$ was lower than that of undoped $\mathrm{TiO}_{2}$ (Navio, 1996) and doped samples prepared by sol-gel methods showed lower photoactivity than those prepared by impregnation of Degussa P-25 (Navio, 1999). Palmisano found doping had little effect on the photocatalytic oxidation of phenol (Palmisano, 1988). It was proposed that the particle size played an important role on photoactivity of Fe-doped $\mathrm{TiO}_{2}$ - the samples of diameters $\leq 11 \mathrm{~nm}$ improved photoactivity and its efficiency depending on the dopant concentration (Zhang, 1998). Doping quantum-sized $\mathrm{TiO}_{2}$ with $\mathrm{Fe}^{3+}$ was found to enhance the photoreduction of $\mathrm{CCl}_{4}$ and the photooxidation of $\mathrm{CHCl}_{3}$ (Choi, 1994).

Co-precipitated $\mathrm{Cr}$ (III)-doped $\mathrm{TiO}_{2}$ (mainly anatase) was found to accelerate the photoreduction reaction of dinitrogen, however, depending on dopant content and the initial $\mathrm{pH}$ of the dispersion, it was found to decrease 
or not change the photodegradation of phenol (Martin, 1992). For the photodegradation of Rhodamine B, $\mathrm{Cr}^{3+}$ doped $\mathrm{TiO}_{2}$, with particle size of $10-18 \mathrm{~nm}$ and surface area of $40-50 \mathrm{~m}^{2} \mathrm{~g}^{-1}$, showed lower photoactivity than undoped one (Wilke, 1999). The photoactivity of $\mathrm{Cr}$ doped anatase, made by wet impregnation by $\left(\mathrm{NH}_{4}\right)_{2} \mathrm{Cr}_{2} \mathrm{O}_{7}$, was found to decrease with increasing $\mathrm{Cr}$ content (Fountzoula, 1997). Doping quantum-sized $\mathrm{TiO}_{2}$ (anatase) with $\mathrm{V}^{4+}$ was found to enhance the photoactivity for the oxidation of $\mathrm{CHCl}_{3}$ and oxidation of $\mathrm{CCl}_{4}$ (Choi, 1994) but $\mathrm{V}(\mathrm{V})$ doped $\mathrm{TiO}_{2}$ (mixture of anatase and rutile) exhibited significantly reduced photoactivity in photodegradation of some organic acids: methanoic acid, ethanoic acid and benzoic acid (Paola, 2004).

Therefore, we present results of a systematic study on the optical and photoactivity of nanoparticulate rutile doped with chromium, iron and vanadium at levels from $0.001-1 \mathrm{~mol} \%$. Further in order to investigate the influence of dopant location, two different methods (co-precipitation and impregnation) were employed to prepare the doped $\mathrm{TiO}_{2}$. The structure was studied by X-ray diffraction (XRD). The optical properties were measured by reflectance spectroscopy. The photoactivity was determined by the oxidation of isopropanol and photogreying.

\section{Experimental}

\subsection{Preparation of Doped Titanium Dioxide Powders}

Undoped $\mathrm{TiO}_{2}$ was prepared by the hydrolysis of $5 \mathrm{M}$ aqueous solution of $\mathrm{TiCl}_{4}$ which was added dropwise to sodium hydroxide solution. The resulting titania suspension was heated to $\sim 80{ }^{\circ} \mathrm{C}$ and held at this temperature for two hours. The suspension was then neutralised, the precipitate filtered from solution and washed to remove undesired ions. Finally it was dried at $110{ }^{\circ} \mathrm{C}$ for $16 \mathrm{~h}$ and ground to fine powder. The same chemical route was used to synthesize co-precipitated doped samples by adding the required molar amount of $\mathrm{Fe}, \mathrm{Cr}$ or $\mathrm{V}$ in the form of solutions of $\mathrm{CrCl}_{3}, \mathrm{VOCl}_{3}$ and $\mathrm{Fe}(\mathrm{acac})_{3}$ (all analytical grade) to the $\mathrm{TiCl}_{4}$ solution. Impregnated doped samples were prepared by addition of the corresponding solutions immediately prior to filtration of the neutralised suspension.

Catalysts prepared by co-precipitation are designated as $\mathrm{M}-\mathrm{CP}$, those prepared by impregnation are designated M-SD. In each case a numerical suffix indicates the nominal metal ion content. In both preparation processes, the target levels of metal, $\mathrm{M}$, were $0.001,0.005,0.01,0.1$ or $1 \%$ calculated as the molar ratio of doped metal to Ti.

\subsection{Characterisation of the Sample}

X-ray Diffraction (XRD). Powder diffractograms were recorded from $2 \theta=20^{\circ}$ to $2 \theta=75^{\circ}$ using a Philip's X'pert powder diffractometer system under the ambient condition. $\mathrm{Cu} \mathrm{K}_{\alpha}$ radiation $(\lambda=0.154 \mathrm{~nm})$ was used with a generator voltage of $40 \mathrm{kV}$ and a current $40 \mathrm{~mA}$. The average crystallite size, $\mathrm{D}$, was estimated from the full width at half maximum (FWHM) of the XRD peak using Scherrer equation:

$$
D=\frac{k \lambda}{\beta \cos \theta}
$$

where $D$ is crystallite size, $k$ is a constant of $0.89, \lambda$ is X-ray wavelength, $\beta$ is full width at half maximum and $\theta$ is Bragg angle.

Reflectance spectra. Reflectance spectra were recorded on pressed (5 tons) discs using a Hunterlab colorquest II colourmeter.

Photoactivity. The photoactivity of the sample was monitored by measuring the generation of acetone by a suspension of titanium dioxide in isopropanol. Suspensions were made in a small bead-mill. $0.4 \mathrm{~g}$ of titanium dioxide and $40 \mathrm{~mL}$ of isopropanol were put into the mill-pot. Glass ballotini $(50 \mathrm{~g} 180-212 \mu \mathrm{m})$ were added and the suspension was agitated at $900 \mathrm{rpm}$ for 15 mins. The ballotini were then separated from the suspension and were washed several times with isopropanol to ensure no titanium dioxide remained on them. The washings were added to the suspension and the total volume adjusted to $50 \mathrm{~mL}$. The reaction was carried out in a reactor illuminated below Phillips (PL-L 36 W 09 lamps). The acetone content was analysed using a Cambridge GC94 gas chromatography (Chromosorb wax $60 / 80$ mesh column at $70{ }^{\circ} \mathrm{C}$ ).

Photogreying. $5 \mathrm{~g}$ of powder was pre-mixed with $95 \mathrm{~g}$ mineral oil and then milled for 15 minutes. The slurry was added to an airtight sample container, taking care to avoid air bubbles in the sample. After $2 \mathrm{~h} \mathrm{UV}$ radiation the colour of the sample was measured using a colorimeter and the change in $\mathrm{L}$ value from the initial value was recorded (Egerton, 2007). 


\section{Results}

\subsection{Crystallographic Properties}

XRD patterns of the series of V/CP and V/SD samples are shown in Figures 1a and $1 \mathrm{~b}$ respectively. The number shown in the figure is the crystallite size. All diffractograms were characteristic of the rutile form of $\mathrm{TiO}_{2}-$ no any peaks of anatase or of the transition metal dopants were detected. A comparison of the two figures does not reveal any difference in crystal structure and all of the crystallite sizes fell in the range $7.0 \pm 0.5 \mathrm{~nm}$. Thus sample preparation differences have negligible effect on crystal structure. Moreover, $\mathrm{Cr}$ and $\mathrm{Fe}$ doped $\mathrm{TiO}_{2}$ showed similar results.

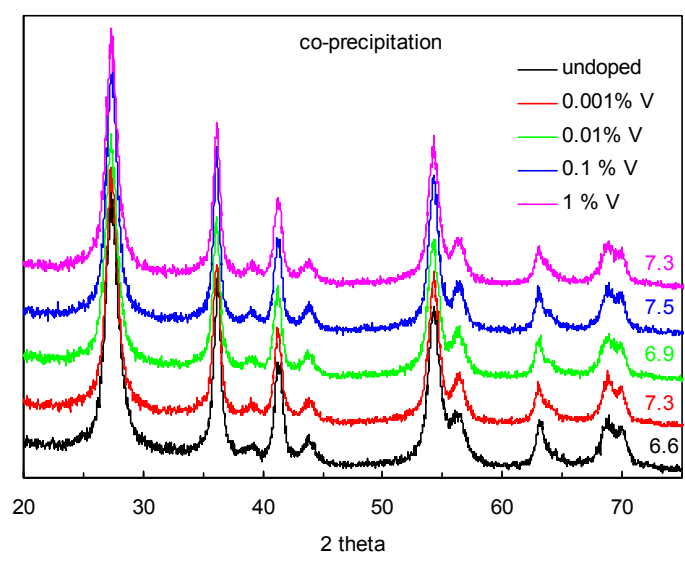

(a)

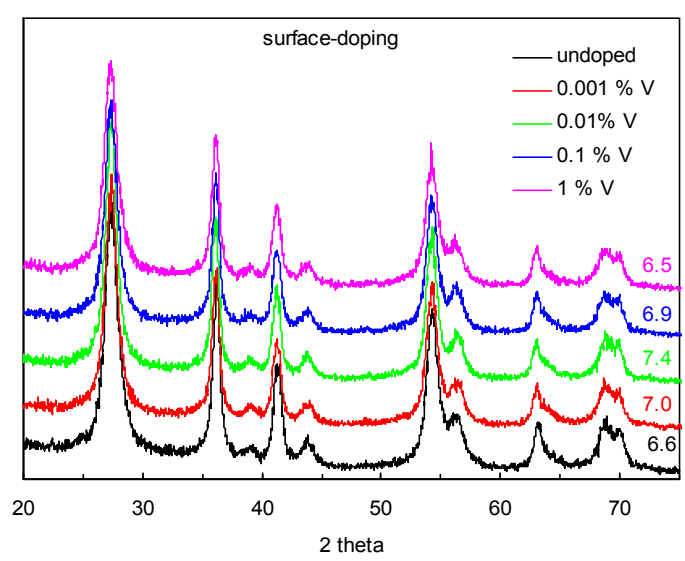

(b)

Figure 1. XRD patterns of (a) co-precipitated and (b) impregnated (surface doped) $\mathrm{V} / \mathrm{TiO}_{2}$

\subsection{Reflectance Spectra}

The effect of transition metal ions on the light absorption of $\mathrm{TiO}_{2}$ was investigated based on the reflectance spectra. Figures $2 \mathrm{a}$ and $\mathrm{b}$ show the diffuse reflectance spectra of $\mathrm{Cr}$-doped $\mathrm{TiO}_{2}$ synthesised by co-precipitation and impregnation (surface-doping) processes, respectively. The spectrum of undoped $\mathrm{TiO}_{2}$ showed high reflectance in the visible range but both co-precipitated and surface doped samples showed increasing absorption in the visible region of the spectrum. A comparison of Figure $2 \mathrm{a}$ with $2 \mathrm{~b}$ demonstrates that the reflectance spectra of the samples are not sensitive to the preparation methods. Both series of samples showed similar trends. The spectra of the samples with low loading (0.001 to 0.01) are similar, whereas, two distinct absorption maxima one at $\sim 420 \mathrm{~nm}$ and one at $\sim 625$ may be seen when the concentration was increased to $1 \%$.

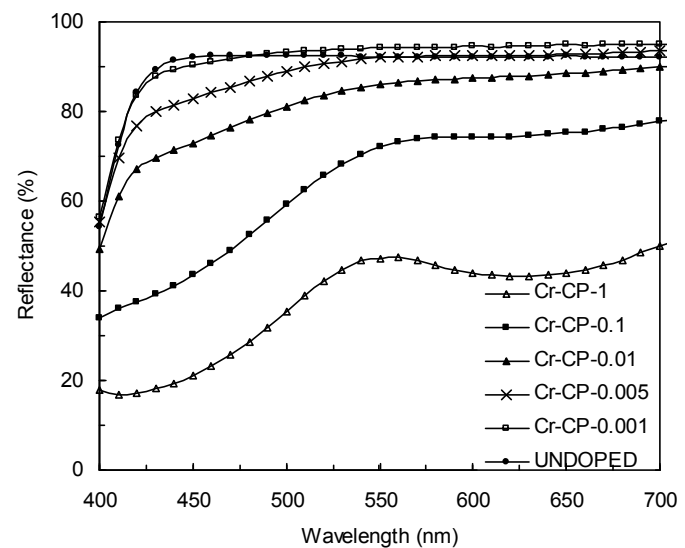

(a)

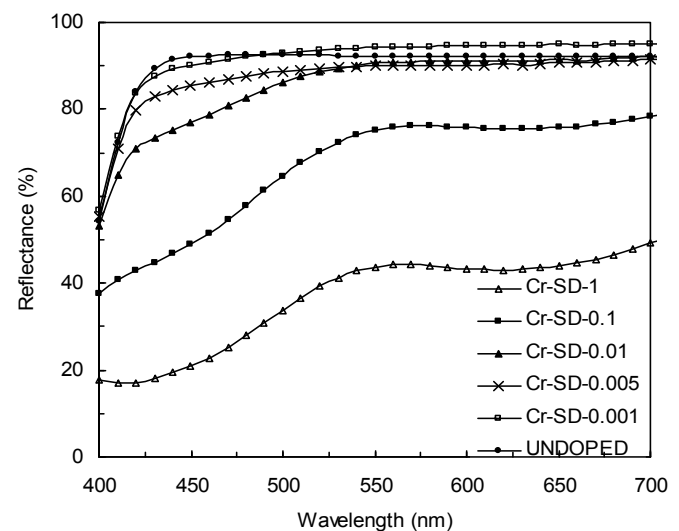

(b)

Figure 2. Reflectance spectra of (a) co-precipitated and (b) impregnated $\mathrm{Cr} /$ doped $\mathrm{TiO}_{2}$ 
The corresponding results for vanadium doped $\mathrm{TiO}_{2}$ are shown in Figures $3 \mathrm{a}$ and $\mathrm{b}$. Unlike those of chromium, the spectra of V-doped $\mathrm{TiO}_{2}$ depended on the preparation method. The reflectance of surface-doped $\mathrm{TiO}_{2}$ was much higher than that of corresponding co-precipitated. For impregnated samples a shoulder to the absorption edge became increasingly prominent as the vanadium concentration increased. However no distinct absorption maximum was evident in the visible region. By contrast for co-precipitated samples an absorption component with a maximum at $425-450 \mathrm{~nm}$ occurred at the highest doping levels and probably contributes to the shoulder seen at lower vanadium levels.

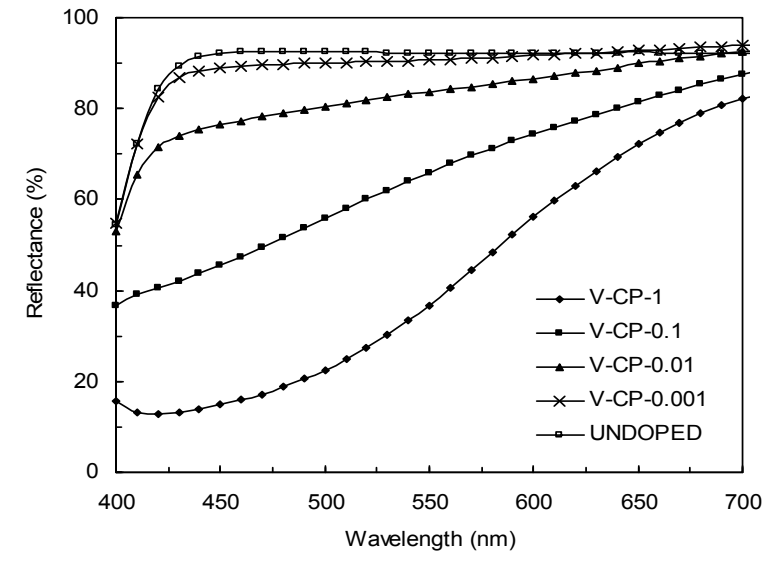

(a)

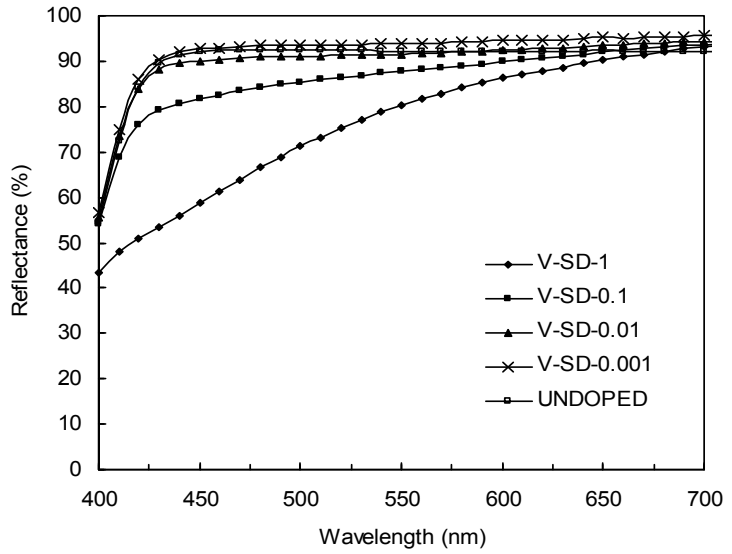

(b)

Figure 3. Reflectance spectra of (a) co-precipitated and (b) impregnated $\mathrm{V} /$ doped $\mathrm{TiO}_{2}$

Only the spectra of co-precipitated iron doped samples were measured. At a nominal $0.1 \%$ the spectrum shows a shoulder to the absorption and evidence of a maximum occurring at wavelengths greater than $700 \mathrm{~nm}$ (Figure 4). Moreover, in a sample with high iron content (5\%) two absorption bands at 410 and $500 \mathrm{~nm}$ were observed.

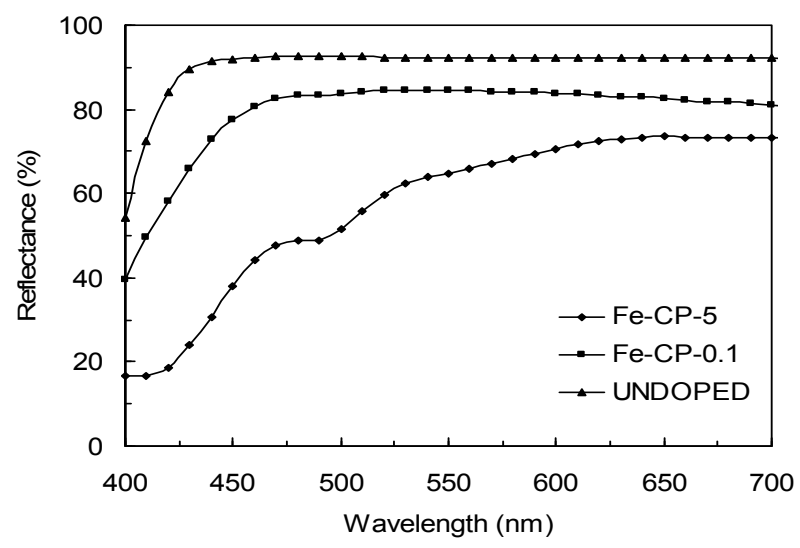

Figure 4. Reflectance spectra of $\mathrm{Fe} /$ doped $\mathrm{TiO}_{2}$

\subsection{Photoactivity}

According to the results in Figure 5, it is clear that the dopant content is an essential variable to define the activity of the samples. The sample shows the maximum photoactivity at the metal doping level range of $0.005-$ $0.01 \%$. When the ion loading was lower than optimal value, the photoactivity increased with increasing doping level. If the ion loading was bigger than this value, the photoactivity was reduced significantly with increasing metal doping level. The relative photoactivity also varied with the doping metal. However, all the samples are in common: the co-precipitated samples showed lower photoactivity than surface doped ones. 


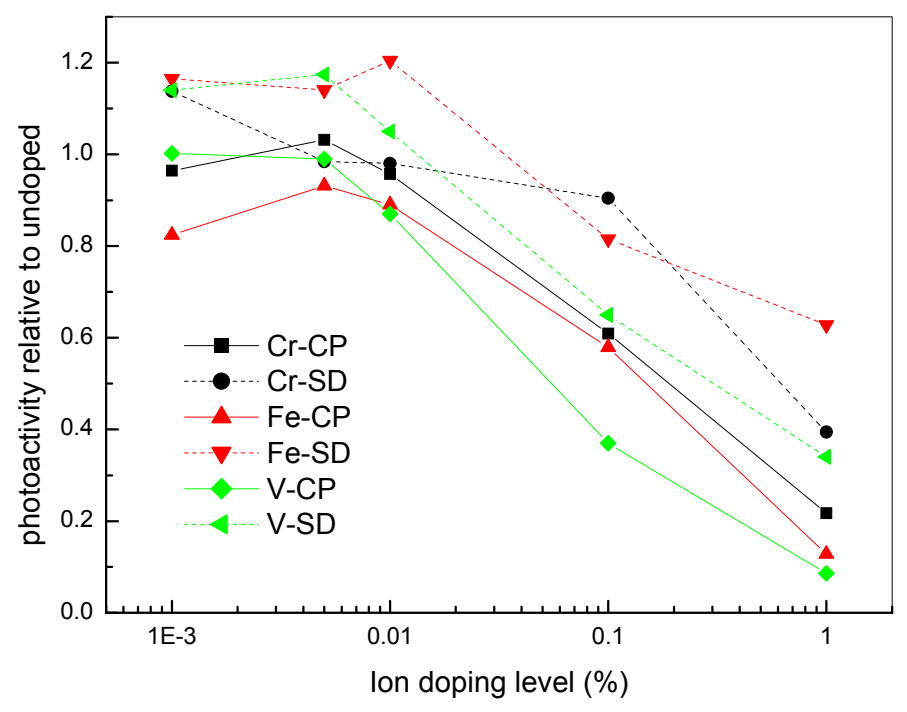

Figure 5. The change of photoactivity with metal doping level

Photogreying has been employed to test the photoactivity of $\mathrm{TiO}_{2}$. Figure 6 compares the results of IPA oxidation and photogreying among samples containing different amounts of chromium. As can be observed, these two sets of results followed the similar trend on the influence of the doping concentration. The photoactivity increased with chromium content until $0.005 \%$ and then decreased again. However, photogreying seems to be more sensitive to the samples with lower doping content than IPA oxidation.

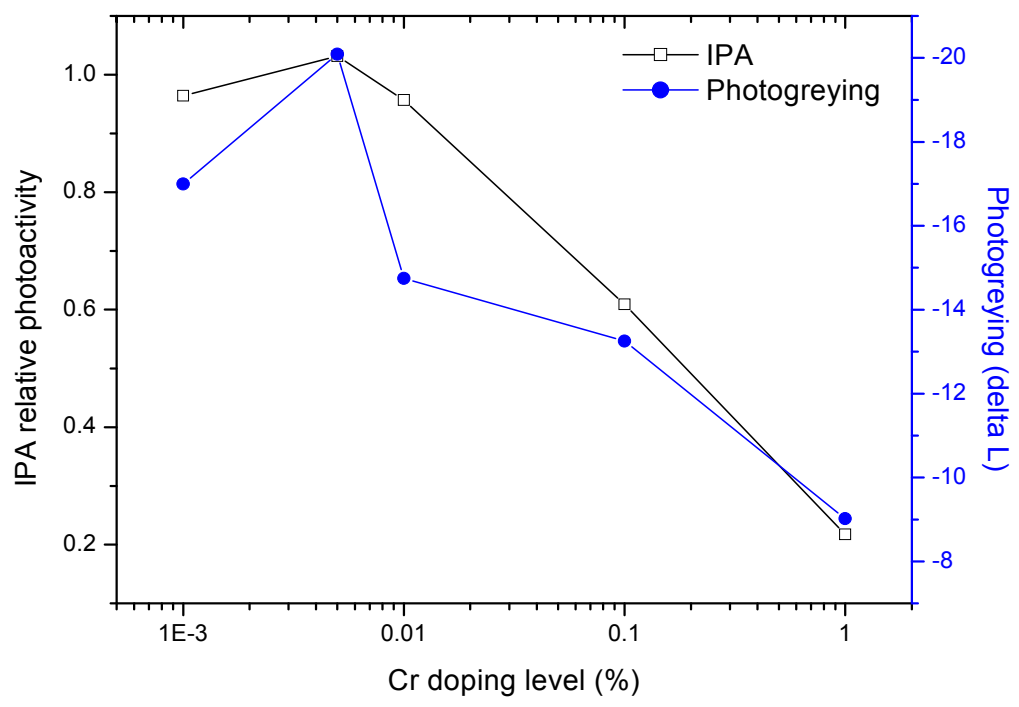

Figure 6. Comparison of IPA and photogreying on the samples with different $\mathrm{Cr}$ contents 


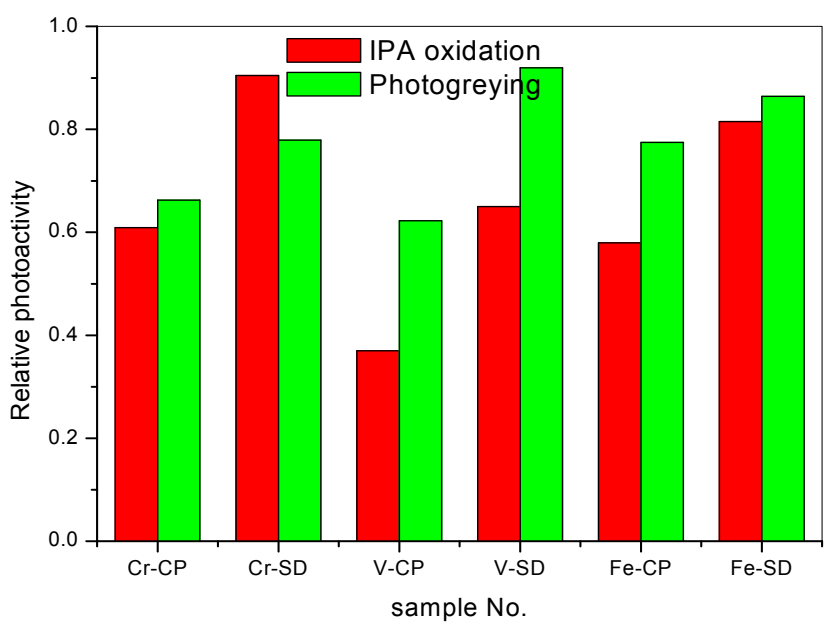

Figure 7. Comparison of IPA and photogreying on the samples with different dopants

The effect of dopant and preparation methods on IPA oxidation and on photogreying is shown in Figure 7. The doping level of the samples was $0.1 \%$., The co-precipitated samples were again less active than surface doped ones for IPA oxidation and the photogreying was also lower. The photoactivity of V-doped samples determined by photogreying is comparative higher than measurement by isopropanol oxidation.

\section{Discussion}

\subsection{Effect of Doping Ion on Phase Structure}

Transition metals act as anatase-to-rutile transformation accelerators or inhibitors (Karvinen, 2003). Cations with a valence below +4 are considered to accelerate the transition, because this provides a charge compensation mechanism for the formation of oxygen vacancies that enhance the transport of atoms in the anatase structure and accelerate the phase transition. Doping cations with a valence above +4 , on the other hand, are considered to retard the transition by forming interstitial $\mathrm{Ti}^{3+}$ cations that suppress atomic transport in the anatase structure (Okada, 2001). According to the XRD data (Figure 1), introducing transition metal did not have significant effect on the structure of the product. Neither anatase nor metal oxides phases could be detected even at highest metal ion loading. Thus, the lack of detection of metal oxides should be attributed to the fact that the phases containing chromium (vanadium or iron) are randomly dispersed within the crystallites, or disordered and possibly amorphous on the $\mathrm{TiO}_{2}$ crystallites, probably the preparation conditions in both sets of samples does not allow diffusion of metal ions and formation of 'bulk' metal oxides. Furthermore, the presence of different amount of transition metal in the $\mathrm{TiO}_{2}$ does not lead to any considerable differences in the crystal size, which was around 7 $\mathrm{nm}$. It was due to the fact that the ionic radii and electronegativity factors do not differ greatly (Huheey, 1983).

\subsection{Effect of Doping Ion on Light Absorption}

$\mathrm{TiO}_{2}$ is photoactive only under ultraviolet light, because of its wide band gap. However, transition metal dopant can extend the absorption to visible wavelength. The absorption of $\mathrm{Cr}$-doped $\mathrm{TiO}_{2}$ increased with $\mathrm{Cr}$ content, together with a change of colour from white to green. The preparation procedure has little effect on the colour of Cr-doped samples. The spectrum of bulk $\mathrm{Cr}_{2} \mathrm{O}_{3}$ includes two absorption bands at 600 and $455 \mathrm{~nm}$ that are ascribed to $\mathrm{A}_{2 \mathrm{~g}} \rightarrow \mathrm{T}_{2 \mathrm{~g}}$ and $\mathrm{A}_{2 \mathrm{~g}} \rightarrow \mathrm{T}_{1 \mathrm{~g}} \mathrm{~d}-\mathrm{d}$ transitions. $\mathrm{Cr}^{3+}$ ions can occupy lattice positions, substituting $\mathrm{Ti}^{{ }^{4+}}$ ions or can be located in interstitial sites, electrical balance being maintained by oxygen vacancies in the second coordination sphere (Martin, 1992). Thus, the existence of $\mathrm{Cr}^{3+}$ cations in different distorted environments can lead to broadening of the $\mathrm{Cr}^{3+} d-d$ transition bands, thus extending their range above $400 \mathrm{~nm}$. The metal-donor atom bonding $\left[\mathrm{MO}_{6}\right]$ is present in octahedral complexes of chromium (3+). The size of $\left[\mathrm{MO}_{6}\right]$ octahedral and titania are different, the distortion of $\mathrm{Cr}^{3+}$ result to a shift of $\mathrm{A}_{2 \mathrm{~g}} \rightarrow \mathrm{T}_{2 \mathrm{~g}}$ band toward to higher wavelength. Thus, two broad absorption regions at about $420 \mathrm{~nm}$ and $625 \mathrm{~nm}$ were observed (Figure 2).

For V-doped $\mathrm{TiO}_{2}$, the spectra of two sets of the samples varied with the preparation procedure. For co-precipitated samples, the spectra of the $\mathrm{V}$-doped $\mathrm{TiO}_{2}$ dramatically changed with the vanadium content. A rise in vanadium content loading led to an increase in the absorption range of 400-550 nm (Figure 3), which is indicative of octahedral V(V) coordination (Hannus, 2001; Gao, 1999). Clearly, a red shift of the wavelength CT 
band with increase vanadium loading is observed. At highest vanadium loading (1\%), strong absorption above $400 \mathrm{~nm}$ suggests the presence of $\mathrm{V}_{2} \mathrm{O}_{5}$. This low-energy absorption might be due to a small amount of polymerised surface vanadium oxide species or due to the synergistic effect when the isolated $\mathrm{V}$ cations bind with polymerised Ti cations. Moreover, the absorption around $625 \mathrm{~nm}$ was due to the reduction of the supported phase with formation of $\mathrm{V}^{4+}$ and of even more reduced vanadium oxide phase (Gao, 1998).

For surface-doped samples, no significant difference could be observed even for vanadium loading up to $0.1 \%$. The slight modification of spectra with respect to that of undoped $\mathrm{TiO}_{2}$ is due to the higher degree of interaction between the vanadium ions and the surface of $\mathrm{TiO}_{2}$ species. In co-precipitated $\mathrm{V}$ samples a broad band occurred which did not occur in $\mathrm{TiO}_{2}$ surface-additioned with vanadium. This correlates with the whiter appearance of V-SD-1.

Fe doped $\mathrm{TiO}_{2}$, similarly, showed higher visible-absorption than the undoped, and this absorption increased with the iron content, together with changes on colour from white to yellow. Moreover, surface-doped samples are slightly more coloured than those prepared by the co-precipitation process. The spectrum of Fe-CP-5 in Figure 4 was found similar to that of hematite due to the existence of segregated iron phase.

\subsection{Effect of the Doping Ion on the Photoactivity and Photogreying}

Upon UV irradiation, electrons and holes can be generated in the conduction and valence bands of $\mathrm{TiO}_{2}$. The photogenerated electrons and holes can either migrate to the surface or recombine. At the surface, photogenerated electrons can reduce an electron acceptor and photogenerated holes can oxidise an electron donor Recombination of these charge carriers can occur in the bulk or at the surface. For any photocatalytic reaction the lifetimes of electrons and holes must be long enough to allow them to reach the surface of the photocatalysts. Thus, the photoactivity depends on the competition between the formation of electron/hole pairs and the recombination. By incorporation of transition metal ions new trapping sites are introduced which affect the electron/hole recombination rates (Choi, 1994).

For all the dopants tested in this study an optimum doping loading appeared with regards to the photoactivity, which as observed in quantum-sized doped $\mathrm{TiO}_{2}$. At loadings below the optimum concentration, the photoactivity increased with increasing doping level. This may be due to the fact that the fewer trap sites were available. On the other hand, photoactivity decreased with an increasing doping content when the doping level is higher than optimum amount. It could be explained by the followings. As the average distance between recombination centres decreased with increasing dopant content, so the recombination rate increased, then the photoactivity decreased. In the presence of transition metal, the reduction of surface hydroxyl groups may also contributed to the low photoactivity (Choi, 1994). Therefore, the effect of a transition metal is a balance between its ability to act as an efficient trap site or as a recombination center.

Charge-transfer reactions are slow process and also influence the photoactivity. In quantum-sized (2-4 nm) particles, due to the lack of band bending, both electron and holes are readily available at the interface (or very close to it) (Choi, 1994). Oxidation reaction by holes and reduction reaction by electrons can occur simultaneously with a consequently high photoactivity. In the current study, the crystal size is around $7 \mathrm{~nm}$ and the particle size is 50-60 nm long and $10 \mathrm{~nm}$ wide. Dopant ions can be further from the surface, the chance of transferring trapped charge carriers, thus, becomes much lower. Furthermore, the preparation procedure can induce the formation of defect site acting as recombination centres or can give different surface morphologies (such as hydroxyl density) which can modify the interfacial electron-transfer rates. More dopant ions may be located on the surface in the surfaced-additioned samples than in the co-precipitated samples. Because, surface transition ions are more likely to act as a surface-trap site than as a recombination centres the photoactivity of surface-additioned $\mathrm{TiO}_{2}$ would be higher than that of the co-precipitated $\mathrm{TiO}_{2}$ in which transition ions are in the bulk.

In this study, the photoactivity was determined by both isopropanol (IPA) oxidation and photogreying test. The former was based on the photo-oxidation, the latter on photo-reduction. The photoactivity measured by IPA oxidation follows the order: $\mathrm{Cr}^{3+}>\mathrm{Fe}^{3+}>\mathrm{V}^{5+}$, while photogreying test showed the reverse order: $\mathrm{V}^{5+}>\mathrm{Fe}^{3+}>$ $\mathrm{Cr}^{3+}$. Photogreying in the absence of oxygen results from the trapping of photogenerated electrons by $\mathrm{Ti}^{4+}$ within or at the surface of the $\mathrm{TiO}_{2}$ lattice to form $\mathrm{Ti}^{3+}$ ions which are grey-blue and are measured as photogreying. In Fe-doped $\mathrm{TiO}_{2}$, surface $\mathrm{Fe}^{3+}$ can trap electrons, as well as holes, because the $\mathrm{Fe}^{3+} / \mathrm{Fe}^{2+}$ level lies close to the $\mathrm{Ti}^{3+} / \mathrm{Ti}^{4+}$ level (Mizushima, 1972). The trapped electron in $\mathrm{Fe}^{2+}$ can be transferred to a neighbouring surface $\mathrm{Ti}^{4+}$ to form the $\mathrm{Ti}^{3+}$. By contrast, in $\mathrm{Cr}$-doped $\mathrm{TiO}_{2}$, hole trapping of $\mathrm{Cr}^{3+}$ is favourable because the $\mathrm{Cr}^{4+} / \mathrm{Cr}^{3+}$ level is located within the band gap. The resulting $\mathrm{Cr}^{4+}$ centres, corresponding to these trapped holes can subsequently trap an electron and in this way they act as recombination centres. In V-doped samples, the stable closed electron 
shell configuration of $\mathrm{V}^{5+}\left(\mathrm{d}^{0}\right)$ makes hole trapping unfavourable but electron-trapping is facilitated because the $\mathrm{V}^{5+} / \mathrm{V}^{4+}$ energy level is within the $\mathrm{TiO}_{2}$ band gap. This tendency of $\mathrm{V}^{5+}$ to trap electrons, of $\mathrm{Cr}^{3+}$ to trap holes, and $\mathrm{Fe}^{3+}$ to trap both, is consistent with the different pattern of activities for photogreying and for IPA oxidation.

Therefore, the photoactivity of doped $\mathrm{TiO}_{2}$ is determined by many physicochemical and electronic parameters, such as the band gap, the energy level, electron shell configuration of the dopant, the number of active sites, the amount of $\mathrm{OH}$ surface groups, the existence of separated ions or mixed phase, which are difficult to be correlated. The photoactivity derives from a balance of these factors, some of which often play contrasting roles, therefore, it is difficult to predict a good dopant.

\section{Conclusions}

Transition metal doped $\mathrm{TiO}_{2}$ was successfully synthesised by two different routes: co-precipitation and surface addition processes. Introducing transition metal did not change on the crystal structure of $\mathrm{TiO}_{2}$. No bulk metal oxides could be detected from XRD measurement which indicating the good dispersion of oxides into $\mathrm{TiO}_{2}$. The light absorption edge was red shifted to the visible range due to the charge transfer between a dopant and conduction band (valance band) or a d-d transition in the crystal field. The photoactivity was significantly reduced by doping with transition metal. The photoactivity was related to the dopant concentration, the energy level of dopant, the number of active site and the existence of oxides phase. Preparation technique is another parameter determining the photoactivity. Co-precipitation is more efficient technique on reducing the photoactivity of doped $\mathrm{TiO}_{2}$. These factors affect IPA photooxidation as well as photogreying, but not to the same extent.

\section{Acknowledgements}

This work was carried within the ACORN collaboration of the IMPACT Faraday Partnership. We thank both the EPSRC and the UK Department of Trade and Industry for funding and both Ian Tooley (Croda) and Robert Eveson (DuPont Teijin Films) for their specific support of this project.

\section{Reference}

Chen, J., Yao, M., \& Wang, X. (2008). Investigation of transition metal ion doping behaviours on $\mathrm{TiO}_{2}$ nanoparticles. J. Nanopart. Res., 10, 871-875. http://dx.doi.org/10.1007/s11051-007-9237-3

Choi, W., Termin, A., \& Hoffmann, M. R. (1994). The role of metal ion dopants in quantum-sized $\mathrm{TiO}_{2}$ : correlation between photoreactivity and charge carrier recombination dynamics. J. Phys. Chem., 98, 13669-13679. http://dx.doi.org/10.1021/j100102a038

Egerton, T. A., Kessell, L. M., Tooley, I. R., \& Wang, L. (2007). Photogreying of $\mathrm{TiO}_{2}$ nanoparticles. $J$. Nanoparticles Res., 9(2), 251-260. http://dx.doi.org/10.1007/s11051-006-9195-1

Fountzoula, Ch., Matralis, H. K., Papadopoulou, Ch., Voyiatzis G. A., \& Kordulis, Ch. (1997). The influence of the chromium content on the physicochemical properties and the catalytic behaviour of $\mathrm{CrO}_{\mathrm{x}} / \mathrm{TiO}_{2}$ catalysts for the selective catalytic reduction of nitric oxide by ammonia at relatively high temperatures. J. Catal., 172, 391-405. http://dx.doi.org/10.1006/jcat.1997.1845

Gao, X., Bare, S. R., Fierro, J. L. G., \& Wachs, I. E. (1999). Structural characteristics and reactivity/reducibility properties of dispersed and bilayered $\mathrm{V}_{2} \mathrm{O}_{5} / \mathrm{TiO}_{2} / \mathrm{SiO}_{2}$ catalyst. J. Phys. Chem. B., 103, 618-629. http://dx.doi.org/10.1021/jp983357m

Gao, X., Bare, S. R., Weckhuysen, B. M., \& Wachs, I. E. (1998). In situ spectroscopic investigation of molecular structures of highly dispersed vanadium oxide on silica under various conditions. J. Phys. Chem. B, 103, 10842-10852. http://dx.doi.org/10.1021/jp9826367

Hannus, I., Toth, T., Mehn, D., \& Kiricsi, I. (2001). UV-vis diffuse reflectance spectroscopic study of transition-metal (V, Ti) containing catalysts. J. Mol. Struct., 563-564, 279-282. http://dx.doi.org/10.1016/S0022-2860(01)00439-2

Huheey, J. E. (1983). Inorganic chemistry, Principles of structure and reactivity. New York, NY: Harper \& Row.

Ikeda, S., Sugiyama, N., Pal, B., Marci, G., Palmisano, L., Noguchi, H., ... Ohtani, B. (2001). Photocatalytic activity of transition-metal-loaded titanium(IV) oxide powders suspended in aqueous solutions: Correlation with electron-hole recombination kinetics. Phys. Chem. Chem. Phys., 3, 267-273. http://dx.doi.org/10.1039/B008028O

Karvinen, S. (2003). The effects of trace elements on the crystal properties of $\mathrm{TiO}_{2}$. Solid State Sci., 5, 811-819. http://dx.doi.org/10.1016/S1293-2558(03)00082-7 
Karvinen, S., \& Lamminmaki, R. J. (2003). Preparation and characterisation of mesoporous visible-light-active anatase. Solid State Sci., 5, 1159-1166. http://dx.doi.org/10.1016/S1293-2558(03)00147-X

Khan, R., Kim, S. W., \& Kim, T. J. (2008). Synthesis and Control of Physical Properties of Titania Nanoparticles as a Function of Synthetic Parameters. J. Nanosci. Nanotechnol., 8, 4738-4742. http://dx.doi.org/10.1166/jnn.2008.IC56

Martin, C., Martin, I., Rives, V., Palmisano L., \& Schiavello, M. (1992). Structural and surface characterisation of the polycrystalline system $\mathrm{Cr}_{\mathrm{x}} \mathrm{O}_{\mathrm{y}} \mathrm{TiO}_{2}$ employed for photoreduction of dinitrogen and photodegradation of phenol. J. Catal., 134, 434-444. http://dx.doi.org/10.1016/0021-9517(92)90333-D

Mizushima, K., Tanaka, M., \& Iila, S. (1972). Energy levels of iron group impurities in $\mathrm{TiO}_{2}$. J. Phys. Soc. Jpn., 32, 1519-1524. http://dx.doi.org/10.1143/jpsj.32.1519

Navio, J. A., Colon, G., Litter, M. I., \& Bianco, G. N. (1996). Synthesis, characterization and photocatalytic properties of iron-doped titania semiconductors prepared from $\mathrm{TiO}_{2}$ and iron(III) acetylacetonate. J. Mol. Catal. A, 106, 267-276. http://dx.doi.org/10.1016/1381-1169(95)00264-2

Navio, J. A., Testa, J. J., Djedjeian, P., Padron, J. R., Rodriguez, D., \& Litter, M. I. (1999). Iron-doped titania powders prepared by a sol-gel method. Part II: photocatalytic properties. Appl. Catal. A, 178, 191-203. http://dx.doi.org/10.1016/S0926-860X(98)00286-5

Nunes, M. R., Monteiro, O. C., Castro, A. L., Vasconcelo, D. A., \& Silvestre, A. J. (2008). A new chemical route to synthesise $\mathrm{TM}$-doped $(\mathrm{TM}=\mathrm{Co}, \mathrm{Fe}) \quad \mathrm{TiO}_{2}$ nanoparticles. Eur. J. Inorg. Chem., 961-965. http://dx.doi.org/10.1002/ejic.200700978

Okada, K., Yamamoto, N., Kameshima, K., Yasumori, A., \& MacKenzie, K. (2001). Effect of silica additive on the anatase-to-rutile phase transition. J. Am. Ceram. Soc., 84, 1591-1596. http://dx.doi.org/10.1111/j.1151-2916.2001.tb00882.x

Palmisano, L., Augugliaro, V., Sclafani, A., \& Schiavello, M. (1988). Activity of chromium-ion-doped titania for the dinitrogen photoreduction to ammonia and for the phenol photodegradation. J. Phys. Chem., 92, 6710-6713. http://dx.doi.org/10.1021/j100334a044

Paola, A. D., Garcia-Lopez, E., Marci, G., Martin, C., Palmisano, L., Rives V., \& Venezia, A. M. (2004). Surface characterisation of metal ions loaded $\mathrm{TiO} 2$ photocatalysts: structure-activity relationship. Appl. Catal. B, 48, 223-233. http://dx.doi.org/10.1016/j.apcatb.2003.10.015

Soria, J., Conesa, J. C., Augugliaro, V., Palmisano, L., Schiavello, M., \& Sclafani, A. (1991). Dinitrogen photoreduction to ammonia over titanium-dioxide powders doped with ferric ions. J. Phys. Chem., 95, 274-282. http://dx.doi.org/10.1021/j100154a052

Wang, C. Y., Bottcher, C., Bahnemann, D. W., \& Dohrmann, J. K. (2003). A comparative study of nanometer sized $\mathrm{Fe}(\mathrm{III})$-doped $\mathrm{TiO}_{2}$ photocatalysts: synthesis, characterization and activity. J. Mater. Chem., 13, 2322-2329. http://dx.doi.org/10.1039/B303716A

Wilke, K., \& Breuer, H. D. (1999). The influence of transition metal doping on the physical and photocatalytic properties of titania. J. Photochem. Photobiol., A 121, 49-53. http://dx.doi.org/10.1016/S1010-6030(98)00452-3

Yang, Z., Yin, L., Ou, E., Wang, Y., Peng, L., \& Wang, J. (2008). Transition metal doped mesoporous titania with a crystalline framework as catalysts for oxidation of p-bromotoluene to pbromobenzaldehyde. Front. Chem. Eng. China, 2, 296-300.

Zhang, Z., Wang, C-C., Zakaria, R., \& Ying, J. Y. (1998). Role of particle size in nanocrystalline $\mathrm{TiO}_{2}$-based photocatalysts. J. Phys. Chem. B, 102, 10871-10878. http://dx.doi.org/10.1021/jp982948+ 